\title{
La certificación de reumatólogo, experiencia en México
}

\section{Alejandro Arce Salinas, Virginia Pascual Ramos \\ Consejo Mexicano de Reumatología (CMR), A.C.}

\section{Correspondencia:}

\section{Dra. Virginia Pascual Ramos}

”virtichu@gmail.com

Palabras clave: reumatología, certificación, México.

A lo largo de la historia, la sociedad ha buscado garantizar que la actividad médica sea benéfica y cuente con un marco regulatorio que guíe su actuación; antiguamente mediante códigos éticos y deontológicos y más recientemente, mediante mecanismos de rendición de cuentas y de evaluación de resultados como son los procesos de certificación o acreditación. Los primeros códigos éticos en medicina se remontan al siglo XVIII antes de Cristo, como el Código de Hammurabi el cual contenía 10 Normas y 282 reglas que regulaban el ejercicio de la medicina. Con el paso de los siglos, se impusieron cambios de orden filosófico y estructural que condicionaron las bases de la sociedad actual, entre los que cabe mencionar la enseñanza de la medicina fuera de los claustros religiosos, la semilla del positivismo como filosofía del pensamiento médico, la imposición del método científico en el quehacer médico y la expansión del conocimiento de las enfermedades, los procedimientos quirúrgicos y las maniobras de prevención. Los cambios anteriores y más recientemente, la integración a la medicina de terceros interesados como la industria farmacéutica y la medicina pre-pagada consolidaron la exigencia actual de la sociedad, de que los actos médicos se realicen dentro de marcos bioéticos claros y siempre con el bienestar del paciente como centro de todo su quehacer.

Los orígenes de los Consejos tal y como los reconocemos actualmente, se remontan a 1916, cuando un grupo de oftalmólogos en Norteamérica conformaron el primer Consejo de especialidad con la labor de verificar las capacidades y la actualización de sus colegas; este ejemplo permeó rápidamente a otros gremios de especialistas dentro y fuera del continente. En México, el primer Consejo de especialidades médicas se fundó el 13 de febrero de 1963, firmándose ante notario el Consejo Mexicano de Médicos Anatomopatólogos, A.C. Este hecho trascendente fue observado con interés por la Academia Nacional de Medicina quien en años subsecuentes, discutió la reglamentación de especialidades, la certificación de especialistas y la organización de los diferentes Consejos de especialidades médicas.

El Consejo Mexicano de Reumatología (CMR) fue fundado el 10 de febrero de 1975. Durante 23 años fue la propia Academia Nacional de Medicina quien proporcionó el aval y el soporte académico a todos los Consejos; en 1995 se fortaleció con la creación del Comité Normativo Nacional de Consejos de Especialidades Médicas (CONACEM); en la actualidad, es una organización integrada por la Academia Nacional de Medicina, la Academia Mexicana de Cirugía y los 47 actuales Consejos de Especialidades Médicas. La función del CONACEM es regular y unificar los procesos de certificación y recertificación (o certificación vigente) de los diferentes Consejos toda vez que éstos hayan recibido la idoneidad tras un escrupuloso y actualizado proceso que conlleva la revisión de los documentos elaborados por los 
propios Consejos (como son estatutos, manual de procedimientos y código de ética), de las credenciales de los integrantes de cada Consejo y de los procesos de certificación y certificación vigente. El CMR es un cuerpo colegiado, integrado actualmente por 11 consejeros y un consejero asesor, todos ellos reumatólogos certificados, quienes ejercen la profesión en diferentes áreas del sistema de salud mexicano (público y privado), con cierta representación geográfica del país y con interés en la formación de especialistas. Para formar parte del CMR se deben de cumplir ciertos requisitos, debidamente publicados en la página web correspondiente (www.consejoreumatologia.org). A lo largo de su historia, el CMR ha certificado 768 reumatólogos de adultos.

En México, la Ley General de Salud (1) asienta que los Consejos deben de establecer un periodo de exámenes anualmente, para la certificación de especialista (y para la recertificación). En una encuesta realizada por el CONACEM, se hizo evidente la falta de uniformidad en los requisitos solicitados, el tipo de examen aplicado (oral, escrito, práctico o combinación de los anteriores) o el número y clase de reactivos del examen teórico.

Para obtener la certificación (de primera vez) en Reumatología, tradicionalmente el CMR ha aplicado un examen teórico y un examen práctico al término del curso académico de los sustentantes, en dos días consecutivos. Esta primera certificación, al igual que las posteriores recertificaciones tiene una validad actual de 5 años. Ambas evaluaciones han sufrido cambios a lo largo de la existencia de nuestro Consejo. Los más recientes han sido propiciados por un intento de apegarse a las normas oficiales dictadas por CONACEM y por el cambio en el modelo educativo a nivel mundial, que México ha adoptado y que está basado en competencias $(2,3)$.

El examen teórico ha incluido tradicionalmente de 200 a 300 preguntas y en la última década se ha modificado hacia la inclusión de casos clínicos, con 4 a 5 preguntas de opción múltiple (1 respuesta correcta, 3 distractores), limitando el número de pre- guntas de conocimiento aislado o memorístico para privilegiar el razonamiento clínico y la resolución de problemas, actividades taxonómicamente más elevadas de acuerdo con la pirámide de Miller (4). De manera paralela, se han realizado esfuerzos para mejorar la calidad de la elaboración de los casos clínicos a través de seleccionar a reumatólogos con experiencia y que hayan asistido a cuando menos une sesión impartida por el CMR sobre la elaboración de reactivos para evaluación de conocimientos médicos (tres horas de duración). Todos los casos clínicos deben de cumplir con un formato en el cual se incluyen las oportunas referencias. Los casos son sometidos a revisión por un Comité del CMR compuesto por 3 o 4 consejeros, quienes deciden o no la permanencia de los mismos en el examen nacional. Finalmente, el CMR realiza una evaluación del comportamiento del examen y de cada reactivo por separado con la finalidad de depurar los reactivos mal elaborados y mejorar la calidad de las futuras evaluaciones.

El examen práctico sufrió pocas modificaciones durante 36 años, en los cuales se usó el caso único real con tres sinodales $(5,6)$. El anterior evalúa el desempeño médico en escenarios reales, verifica las capacidades del sustentante para obtener información útil, tomar decisiones apropiadas, integrar conocimientos previos y discutir puntos de vista. Sin embargo, es poco confiable y reproducible (7). A partir del año 2012, el CMR implementó un examen clínico objetivo estructurado (ECOE). Los motivos fundamentales para iniciar dicha empresa fueron el conocimiento de que se trata de una herramienta (más) objetiva, que permite examinar competencias y un amplio número de habilidades clínicas y de comunicación $(8,9,10)$, en un contexto con pacientes reales o simulados, con una buena experiencia internacional para evaluar médicos generales, cirujanos y pediatras así como reumatólogos (11) y habilidades de ultrasonido músculo-esquelético (12). Además, en México se emplea desde 1996 como examen sumativo en la facultad de medicina de la 
Universidad Nacional Autónoma de México (UNAM) y como la fase práctica del examen profesional de la Licenciatura desde el año 2007. De hecho, fue el departamento de Enseñanza Clínica de la Facultad de Medicina de la UNAM, quien asesoró e impartió las bases teóricas y prácticas a los miembros del CMR encargados de su diseño. Recientemente, publicamos la experiencia de los 2 primeros años (13) en la cual concluimos que "el ECOE diseñado por el CMR mostró adecuadas validez de constructo y confiabilidad, por lo cual puede ser integrado como un instrumento de evaluación de las competencias clínicas en el examen de certificación como reumatólogo".

Este año cumplimos el tercero de su aplicación y reconocemos mejor las fortalezas y debilidades del ECOE; sin duda alguna la mayor debilidad es la gran cantidad de recursos humanos y económicos que requiere así como la necesidad de instalaciones adecuadas. En su preparación y aplicación participan todo el CMR, 20 reumatólogos externos y 15 pacientes, distribuidos en 20 a 25 sesiones de varias horas de duración cada una. Los costos pueden alcanzar los 9200 dólares anuales, aunque hemos tenido la ventaja de contar con el apoyo incondicional (y gratuito) de nuestro gremio y ciertas Instituciones de salud del país como el Hospital Infantil de México Federico Gómez, en el DF. En los tres años, no han faltado "sorpresas" de última hora inherentes al hecho de trabajar con pacientes y aspirantes "reales". Dentro de los logros, hemos ganado en confiabilidad y comprobado la estabilidad de las estaciones al aplicarlas a grupos diferentes en los tres años, a pesar que hemos notado un ajuste del currículo en algunos centros de formación luego de discutir los resultados del examen. También hemos corroborado un año más la validez de constructo y hemos ampliado la evaluación de los aspirantes al agregar una evaluación de las habilidades de comunicación que de hecho ha correlacionado con el desempeño del ECOE (14). Finalmente, hemos implementado una estrategia diferente para establecer el punto de corte de cada estación (y por ende del ECOE), que puede diferenciar mejor el desempeño del alumno en cada estación e incrementar la validez del instrumento (15). Sin embargo, su aplicación requiere de profundizar más en el conocimiento de los componentes que se están midiendo.

Un punto clave para el CMR, fuente de inquietud permanente, es el establecimiento del punto de corte para obtener la acreditación del Consejo. El examen del CMR es un examen de "altas consecuencias" por las implicaciones que tiene para el candidato (en México, la Ley General de Salud exige la certificación y certificación vigente desde marzo del presente año para ejercer la profesión). En la última década, motivados por una educación basada en competencias, hemos adoptado puntos de corte con referencia a criterio (16-18) y abandonado la determinación de puntos de corte con referencia a la norma. Además, hemos aprendido que se requieren de métodos sólidos para establecer los mismos ya que afectan al desempeño de los instrumentos de evaluación. El mayor esfuerzo lo hemos enfocado al ECOE pero reconocemos que tenemos que extenderlo al examen teórico. Ambas herramientas evalúan áreas diferentes de la competencia y deben ser tomadas como complementarias. Pese a los esfuerzos realizados, todos vemos tambalearse nuestras convicciones cuando anunciamos oficialmente los resultados e informamos de los "no acreditados" a los profesores encargados de los centros de formación de residentes del país, con quienes nos reunimos una vez al año.

En resumen, la certificación de médicos especialistas en nuestro país existe desde hace décadas, sin embargo, en los últimos años ha sufrido grandes cambios propiciados por un marco legal fortalecido y un nuevo modelo educativo. Actualmente, los Consejos de especialidades médicas tenemos la gran responsabilidad de servir a la sociedad mexicana, con responsabilidad y trasparencia y garantizarle la calidad de los especialistas encargados de su salud. No obstante, somos igualmente responsables 
de ofrecer un proceso justo de evaluación y acreditación a los futuros especialistas. Tenemos además una posición privilegiada para detectar deficiencias en la formación de los especialistas y en conjunto con las universidades adaptar el currículo a las necesidades de nuestra población. Nuestro mayor reto es contribuir a mejorar la práctica clínica de los especialistas e impactar en los indicadores de salud de nuestro país.

\section{Referencias}

1. ACUERDO por el que se emiten los Lineamientos que se sujetarán el Comité Normativo Nacional de Especialidades Médicas a los que se refiere el artículo 81 de la Ley General de Salud, para la aplicación de lo dispuesto por el artículo 272 Bis y el Título cuarto de dicha Ley. Diario oficial de la Federación del 25 de marzo de 2015.

2. Nasca T, Philibert I, Brigham T, Flynn TC. The next GME accreditation system-Rationale and benefits. New Engl J Med 2012;366(11): 1051-6.

3. Abreu LF et al. Perfil por competencias del Médico General Mexicano. Asociación Mexicana de Facultades y Escuelas de Medicina AC. México 2008.

4. Miller GE. The assessment of clinical skills/ competence/ performance. Acad Med 1990;65(9 Suppl): S63-7.

5. Wass $V$, van Der Vleuten $C$. The metric of medical education. The long case. Med Educ 2004;38: 1176-80.

6. Nweble DI. The observed long-case in clinical assessment. Med Educ 1994;25: 369-73

7. Norcini JJ. The death of the long case? BMJ. 2002;324: 408-9.

8. Wass V, van der Vleuten C, Shatzer J. Jones R. Assessment of clinical competence. The Lancet 2001;357: 945-49.

9. Schuwirth LW, van der Vleuten CP. The use of clinical simulations in assessment. Med Educ. 2003;37: 65-71.

10. Newble D. Techniques for measuring clinical competence: objective structured clinical examination. Medical Educ 2004; 38:199-203.

11. Hassell AB; West Midlands Rheumatology Services and Training Committee. Assessment of specialist registrars in rheumatology: experience of an objective structured clinical examination (OSCE). Rheumatology. 2002;41: 1323-28.

12. Kissin EY, Grayson PC, Cannella AC, Demarco PJ, Evangelisto A, Goyal J, et al. Musculoskeletal ultrasound objective structured clinical examination: an assessment of the test. Arthritis Care Res. 2014;66: 2-6.

13. Pascual Ramos V, Medrano Ramírez G, Solís Vallejo E, Bernard
Medina AG, Flores Alvarado DE, Portela Hernández $M$ et al. Desempeño del examen clínico objetivo estructurado como instrumento de evaluación en la certificación nacional como reumatólogo. Reumatol Clin 2014, Dec 15. doi: 10.1016/j. reuma.2014.10.007.

14. Pascual-Ramos V, Medrano-Ramírez G, Solís-Vallejo E, BernardMedina AG, Flores-Alvarado DE, Portela-Hernández $M$ et al. The Mexican experience of a national accreditation process for rheumatology. Moving toward competency-based evaluation. En preparación.

15. Wilkinson TJ, Newble DI, Frampton CM. Standard setting in an objective structured clinical examination: use of global ratings of borderline performance to determine the passing score. Med Educ 2001;35: 1043-49.

16. Norcini JJ. Standards and reliability: when rules of thumb don't apply. Acad Med 1999;74: 1088-90.

17. Wass V, van der Vleuten $C$, Shatzer J. Jones R. Assessment of clinical competence. The Lancet 2001;357: 945-49.

18. Leyva Barajas YE. Una reseña sobre la validez de constructo de pruebas referidas a criterio. Perfiles Educativos 2011;33: 131-54.

\section{Opina sobre este artículo:}
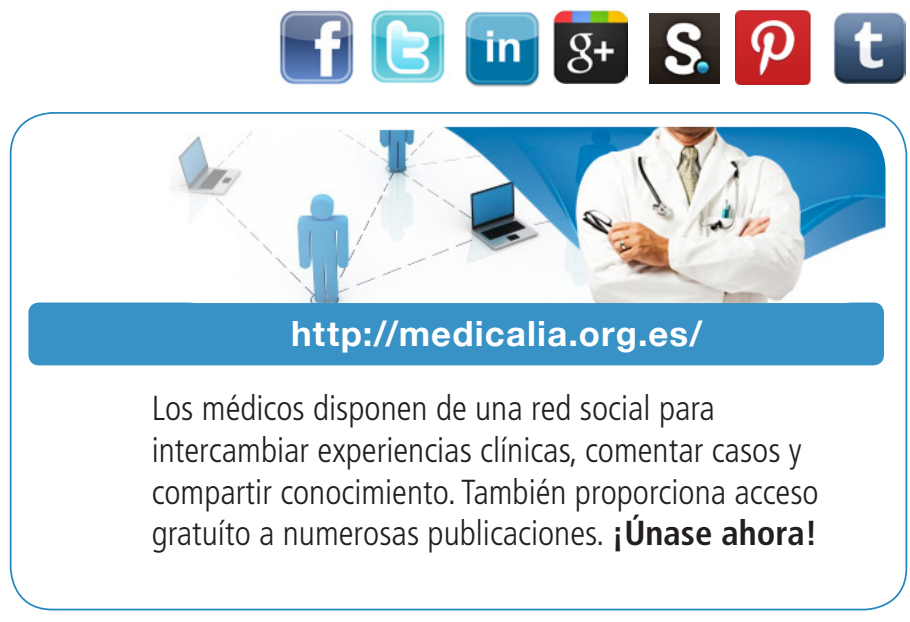

\section{Publish with iMedPub}

\section{http://www.imed.pub}

Acta Reumatológica es una revista que tiene por fin la difusión de estudios clínicos relacionados con aspectos prácticos del diagnóstico, tratamiento y seguimiento de pacientes con patología reumatológica, de estudios epidemiológicos relacionados con patología inflamatoria y musculoesquelética de presentación común o infrecuente en la práctica clínica tanto en población adulta como pediátrica, de casos clínicos de patología poco habitual o de presentaciones inhabituales de patología frecuente, de imágenes didácticas e ilustrativas en reumatología y del estado actual e innovación en la formación especializada en reumatología. 